\title{
Phenolic Composition, Antioxidant Capacity and in vitro Cytotoxicity Assessment of Fruit Wines
}

\author{
Ana Ljevar, Natka Ćurko*, Marina Tomašević, Kristina Radošević, \\ Višnja Gaurina Srček and Karin Kovačević Ganić \\ University of Zagreb, Faculty of Food Technology and Biotechnology, Pierottijeva 6, \\ HR-10000 Zagreb, Croatia
}

Received: April 10, 2015

Accepted: November 30, 2015

\begin{abstract}
Summary
Fruit wines contain a wide range of phenolic compounds with biological effects, but their composition and potential benefits to human health have been studied to the much lesser extent compared to grape wines. The aim of this research is to study the phenolic profile of different types of fruit wines and to evaluate their antioxidant and biological potential. Commercially available fruit wines from blackberry, cherry, raspberry, blackcurrant, strawberry and apple produced in Croatia were analyzed. To the best of our knowledge, this study represents the first comprehensive screening of Croatian fruit wines. The phenolic characterization was performed by spectrophotometry and HPLC-PDA/MS analysis. The antioxidant capacity was determined using ABTS and FRAP assays, while in vitro biological activity was analyzed by the cytotoxicity assay on human breast (MCF-7), colon (CaCo-2) and cervical (HeLa) cancer cell lines. Among the studied fruit wines, blackberry, cherry and blackcurrant wines contained the highest amount of total phenolics, while the last two also contained the highest amount of total anthocyanins. The analysis of individual phenolic compounds showed distinctive phenolic composition of each type of fruit wine, notably as regards anthocyanins. Blackberry, followed by cherry, raspberry and blackcurrant wines also had a significantly higher antioxidant capacity than strawberry and apple wines. Fruit wines inhibited the growth of human cancer cells in vitro in a dose-dependent manner with differing susceptibility among tested cancer cells. Blackberry, cherry, raspberry and blackcurrant wines in the volume ratio of 10 and $20 \%$ showed to be the most effective anti-proliferative agents, with higher susceptibility in HeLa and MCF-7 cells than CaCo-2 cells.
\end{abstract}

Key words: fruit wines, phenolic compounds, antioxidant capacity, cytotoxicity, spectrophotometry, HPLC-PDA/MS

\section{Introduction}

Polyphenols comprise a major group of secondary metabolites found largely in fruits, vegetables, cereals and beverages. From the physiological perspective, they are important compounds for plants and human health. In plants, polyphenols act as protective agents against ultraviolet irradiation or aggression by pathogens (1). There has been an increasing number of evidence that, as anti- oxidants, polyphenols may protect cell constituents against oxidative damage and, therefore, limit the risk of various degenerative diseases associated with oxidative stress (2$4)$. The antioxidant activities of phenolic compounds are mainly attributed to their redox properties, allowing them to act as reducing agents, hydrogen donors and singlet oxygen quenchers. Epidemiological studies have revealed that polyphenols provide significant protection 
against the development of several chronic diseases such as cardiovascular, cancer, diabetes, osteoporosis and neurodegenerative diseases $(5,6)$. Several mechanisms of action have been identified for the chemopreventive effect of polyphenols, including estrogenic/antiestrogenic activity, antiproliferation, induction of cell cycle arrest or apoptosis, prevention of oxidation, induction of antioxidant enzymes, regulation of the host immune system, anti-inflammatory activity and changes in cellular signalling (7). Likewise, polyphenols act as important antioxidants from the oenological point of view, but they also contribute to the wine colour, flavour, astringency and bitterness $(8,9)$.

Fruit wines are rich sources of nutraceuticals that include various types of phenolic compounds. Phenolic compounds in fruit wines include flavonoids (anthocyanins, flavanols, flavonols, etc.) as well as non-flavonoids (derivatives of cinnamic and benzoic acids and stilbenes such as resveratrol). Differences in the composition and quantity of wine polyphenols depend on many factors, such as variety, vintage, geographic area of growth, degree of ripeness at the time of harvest, environmental factors, especially the conditions and methods of vinification and storage. Contrary to grape wines, the phenolic composition of fruit wines has been studied to a much lesser extent, despite the increased production, consumption and popularity of these wines in recent years (10-13). Most of these studies focus on the content of total phenolics and antioxidant capacity, while the ones studying a comprehensive profile of individual phenolic compounds as important markers of wine quality are very scarce and usually involve only one or two different fruit wines, as reported for blackberry (12-15), cherry and blackcurrant (16-19), red raspberry $(20,21)$ and apple wine (11). Nevertheless, some of the fruit wines, such as blackberry $(12,13,22)$ or elderberry, blueberry and blackcurrant wine (23) showed a high phenolic content and antioxidant capacity, even comparable to those of red wine $(12,24)$. In addition, extracts of blackberry, black raspberry, blueberry, cranberry, red raspberry and strawberry, rich in polyphenols, showed important biological activity by inhibiting proliferation of human oral (KB, CAL-27), breast (MCF-7), colon (HT-29, HCT116) and prostate (LNCaP) cancer cells, as well as stimulating cell apoptosis in vitro (25). However, possible health applications of fruit wine phenolic extracts remain to be revealed.

In Croatia, the production of fruit wines does not have a significant place in the overall wine production, but in the last decade different types of fruit wines have been available on the market. Our research has focused on commercially available fruit wines from blackberry, cherry, raspberry, blackcurrant, strawberry and apple produced in Croatia. The objectives of the present study were to determine: $(i)$ the phenolic profile by general spectrophotometric characterization as well as characterization of individual phenolic compounds by high-performance liquid chromatography-photodiode array/mass spectrometry (HPLC-PDA/MS) analyses, (ii) in vitro antioxidant capacity by applying ABTS and FRAP assays, and (iii) in vitro biological potential by the cytotoxicity assay on human breast (MCF-7), colon (CaCo-2) and cervical (HeLa) cancer cell lines.

\section{Materials and Methods}

\section{Chemicals}

Methanol and acetonitrile were of HPLC grade and were purchased from J.T.Baker (Deventer, the Netherlands) and Panreac (Barcelona, Spain). Ethanol, hydrochloric acid and formic acid were purchased from Carlo Erba (Rodano, Italy). Folin Ciocalteu's phenol reagent was purchased from Kemika (Zagreb, Croatia). Sodium bisulfite and sodium carbonate were purchased from Acros Organics (Geel, Belgium), potassium dihydrogen phosphate and iron(III) chloride hexahydrate from POCh (Gliwice, Poland), while phosphoric acid was purchased from Fluka (Buchs, Switzerland). Trolox (6-hydroxy-2,5,7,8-tetramethylchroman-2-carboxylic acid), ABTS [2,2'-azinobis(3-ethylbenzothiazoline-6-sulfonic acid) diammonium salt], potassium peroxodisulfate and iron(II) sulfate heptahydrate were purchased from Fluka (Steinheim, Germany). TPTZ [2,4,6-tris(2-pyridyl)-s-triazine] was purchased from Alfa Aesar (Karlsruhe, Germany). Trypsin-EDTA (0.25\%) and Dulbecco's modified Eagle medium (DMEM) were purchased from Gibco Invitrogen Corporation (Paisley, UK), and fetal bovine serum (FSB) was purchased from Gibco Invitrogen Corporation (Auckland, New Zealand). WST-1 \{4-[3-(4-iodophenyl)-2-(4-nitrophenyl)-2H-5-tetrazolio]-1,3-benzene disulfonate was purchased from Roche (Mannheim, Germany). Acridine Orange, ethidium bromide, Trypan Blue, phosphate buffered saline (PBS) and analytical standards of gallic, protocatechuic, syringic, chlorogenic, $p$-coumaric, ferulic and caffeic acids, (+)-catechin, (-)-epicatechin and quercetin were purchased from Sigma-Aldrich (Steinheim, Germany), while standards of delphinidin-3-glucoside and cyanidin-3-glucoside were purchased from Polyphenols AS (Sandnes, Norway).

\section{Fruit wine samples}

Fruit wines $(N=32)$ from Croatia, commercially available in May 2012, were analyzed in this research, namely blackberry (Rubus fruticosus) $(N=13)$, cherry (Prunus cerasus) $(N=9)$, raspberry (Rubus idaeus) $(N=3)$, blackcurrant (Ribes nigrum) $(\mathrm{N}=2)$, strawberry (Fragaria ananassa) $(\mathrm{N}=2)$ and apple (Malus communis) $(N=3)$ wine samples. More precisely, the sampling of blackberry wines included: one wine vintage 2009 (Kupin, Bubalo, Koprivnica), three wines vintage 2010 (Čuk, OPG Čuković, Grabov potok; Blackberry fruit wine OPG Ćurić, Sveta Nedjelja and Incanto Kostelac, Fructus, Orahovica) and nine wines vintage 2011 (Kupilek, OPG Jabrešić, Klanjec; Sabljak, Sabljak, Bjelovar; Feroz, Feroz, Koprivnica; Kupife, Bokun, Split; Blackberry fruit wine, OPG Sabolović, Bjelovar; Blackberry fruit wine, OPG Petrović, Zaprešić; Biškupin, Biškup, Predavac; Kupinet, Vinko, Ludbreg and Blackberry fruit wine, OPG Matučec, Varaždin). The sampling of cherry wines included: two wines vintage 2008 (Cherry fruit wine, OPG Škudar, Bjelovar and Incanto Kostelac, Fructus, Orahovica), two wines vintage 2009 (Cherry fruit wine, Vilma Banjol, Rab and Cherry fruit wine OPG Škudar, Bjelovar), one wine vintage 2010 (Markesino, OPG Markešić, Bjelovar) and four wines vintage 2011 (Magus, OPG Kolundžić, Bizovac; Cherry fruit wine, OPG Kranjec, Kloštar Podravski; Višnjevina, OPG Bobnjar, Štrigova and Ludbergina utjeha, Vinarija Stručić, 
Ludbreg). The sampling of raspberry wines included: one wine vintage 2009 (Kupife, Bokun, Split) as well as two wines vintage 2010 (Magus, OPG Kolundžić, Bizovac and Malinet, Vinko, Ludbreg). The sampling of blackcurrant wines comprised: one wine vintage 2010 (Blackcurrant fruit wine, Eko-Bobo, Krapina) and one wine vintage 2011 (Blackcurrant fruit wine, Vinko, Ludbreg). The sampling of strawberry wines comprised two wines vintage 2011 (Strawberry fruit wine, Eko-Bobo, Krapina and Čuk, OPG Čuković, Grabov potok). The sampling of apple wines included three wines vintage 2008 (Incanto Kostelac, Fructus, Orahovica; Apple wine OPG Lazić, Cernik and Markesino, OPG Markešić, Bjelovar). Two bottles of each fruit wine were used in this research.

\section{Spectrophotometric analysis of total phenolics and total anthocyanins}

The content of total phenolics was determined using the Folin Ciocalteu reagent (a mixture of phosphotungstic and phosphomolybdic acid) that is reduced with phenolics, forming a blue complex. The absorbance of the blue-coloured solution, measured at $765 \mathrm{~nm}$, is proportional to the content of total phenolics. In order to calculate the content of total phenolics, the calibration curve was constructed using gallic acid as a standard, and the results are expressed in mg of gallic acid equivalents (GAE) per litre (26). The content of total anthocyanins was determined by bisulfite bleaching method (27), since anthocyanins form colourless compounds with bisulfite ion, changing from the red-coloured flavylium cation to the noncoloured form. Total anthocyanin content, expressed in $\mathrm{mg} / \mathrm{L}$, was calculated from the differences in the absorbance between non-bleached and bisulfite-bleached samples, measured at $520 \mathrm{~nm}$ (28). Spectrophotometric analyses were conducted in triplicate.

\section{HPLC analysis of phenolic compounds}

Fruit wine samples were filtered through $0.45-\mu \mathrm{m}$ cellulose acetate filters (Macherey-Nagel GmbH \& Co., Düren, Germany) prior to the injection. Chromatographic analyses were performed on the Varian Pro Star Solvent Delivery System 230 (Varian, Walnut Creek, CA, USA) with a photodiode array detector (PDA) Varian Pro Star 330 and on the Agilent 1100 Series liquid chromatography system (Agilent Technologies, Waldbronn, Germany) with a PDA and single quadrupole mass detector equipped with electrospray ionization interface (G1946D).

Phenolic acids (gallic, protocatechuic, syringic, chlorogenic, $p$-coumaric, ferulic and caffeic acids), flavan-3-ols $[(+)$-catechin and (-)-epicatechin] and flavonol (quercetin) were separated on a Phenomenex Gemini C18 column ( $250 \mathrm{~mm} \times 4.6 \mathrm{~mm}, 5 \mu \mathrm{m}$ i.d.) using water/formic acid (98:2, by volume) (solvent A) and methanol (solvent B). Gradient conditions were: $2-32 \%$ linear gradient $B$ from $0-20$ min, 32-40 \% linear gradient B from 20-30 min, 40-50\% linear gradient B from $30-40 \mathrm{~min}$ and $50 \%$ isocratic gradient B from 40-50 min with re-equilibration of the column for $5 \mathrm{~min}$ under initial gradient conditions; and flow rate of $1 \mathrm{~mL} / \mathrm{min}$. UV-Vis spectra were measured in the wavelength range from 200 to $600 \mathrm{~nm}$. The detection and identification of phenolic compounds were performed at the following wavelengths: $280 \mathrm{~nm}$ (hydroxybenzoic acids and flavan-3-ols), $320 \mathrm{~nm}$ (hydroxycinnamic acids) and $360 \mathrm{~nm}$ (flavonol). The identification and peak assignment of these compounds were based on the comparison of their retention times and UV-Vis spectral data with those of the authentic standards. The quantification was done with calibration curves of authentic external standards listed above, at the wavelength of maximum absorbance $(280,320$ and $360 \mathrm{~nm})$ determined by PDA spectra.

Anthocyanins were separated on a Phenomenex Nucleosil C18 column $(250 \mathrm{~mm} \times 4.6 \mathrm{~mm}, 5 \mu \mathrm{m}$ i.d.) using water/formic acid (95:5, by volume) (solvent $\mathrm{A}$ ) and methanol (solvent B) under gradient conditions previously described to separate anthocyanins in fruit wines $(29,30)$. $\mathrm{UV}-\mathrm{Vis}$ spectra were measured in the wavelength range from 200 to $600 \mathrm{~nm}$. The detection was performed at the wavelength of $520 \mathrm{~nm}$. The identification and peak assignment of anthocyanins were based on the comparison of their retention times, UV-Vis and mass spectral data with those of the standards and published data $(29,30)$. The mass parameters were as follows: capillary voltage 4000 $\mathrm{V}$, drying gas temperature $325^{\circ} \mathrm{C}$, gas flow $\left(\mathrm{N}_{2}\right) 12 \mathrm{~mL} /$ min, operated in positive ion mode scanning from $m / z=50$ to 1500. Following anthocyanins were identified: delphinidin-3-glucoside $\left([\mathrm{M}]^{+}, m / z=465\right)$, delphinidin-3-rutinoside $\left([\mathrm{M}]^{+}, m / z=611\right)$, cyanidin-3-sophoroside $\left([\mathrm{M}]^{+}, m / z=611\right)$, cyanidin-3-glucosylrutinoside ([M] $\left.{ }^{+}, m / z=757\right)$, cyanidin-3-glucoside $\left([\mathrm{M}]^{+}, m / z=449\right)$ and cyanidin-3-rutinoside ([M] ${ }^{+}$, $m / z=595)$. The quantification was done with external standard calibration curves of delphinidin-3-glucoside (for delphinidin-based anthocyanins) and cyanidin-3-glucoside (for cyanidin-based anthocyanins), at the wavelength of maximum absorbance $(520 \mathrm{~nm})$ determined by PDA spectra. All HPLC analyses were conducted in triplicate.

\section{Determination of antioxidant capacity by ABTS and FRAP assays}

The antioxidant capacity of fruit wines was determined by applying an improved ABTS radical cation decolourization assay (31). The blue/green ABTS radical cation chromophore was generated through the reaction between $7 \mathrm{mmol} / \mathrm{L}$ of ABTS stock solution and $2.45 \mathrm{mmol} / \mathrm{L}$ of potassium peroxodisulfate. The addition of antioxidant reduced the ABTS radical cation, where the extent of its decolourization, proportional to the total antioxidant content, was measured at $734 \mathrm{~nm}$ and calculated relative to the reactivity of Trolox as the standard in $\mathrm{mmol} / \mathrm{L}$ of Trolox equivalents (TE) in wine. The FRAP assay was done according to the method of Benzie and Strain (32), where the reduction of ferric to ferrous ion at low $\mathrm{pH}$ causes the formation of the coloured ferrous tripyridyltriazine complex. FRAP values were obtained by comparing the absorbance change at $593 \mathrm{~nm}$ in the reaction mixture with those containing ferrous ions in a known concentration, and expressed in mmol/L of Fe(II) in wine. Analyses of antioxidant capacity by ABTS and FRAP assays were conducted in triplicate.

\section{Cell cultures}

Three human cancer epithelial cell lines: MCF-7, $\mathrm{CaCo}-2$ and HeLa, obtained from the American Type Cul- 
ture Collection (ATCC, Manassas, VA, USA) and grown as adherent cells, were used in this work. Cultivation of these cells was carried out in plastic $\mathrm{T}$ flasks with flat sides for maintenance of cultures, while individual experiments testing the biological activity of fruit wines were performed by using 96-well plates. Cells were maintained in an incubator in the DMEM medium supplemented with $10 \%$ FBS, at $37{ }^{\circ} \mathrm{C}$ and in humidified atmosphere with $5 \% \mathrm{CO}_{2}$.

\section{Determination of in vitro biological activity by cytotoxicity assay}

The effect of fruit wines on cell proliferation was examined by the water-soluble tetrazolium salt (WST-1; Roche, Mannheim, Germany) assay. Six samples of fruit wines were selected, each made from a different type of fruit: blackberry, cherry, raspberry, blackcurrant, strawberry and apple. MCF-7, CaCo-2 and HeLa cells in the exponential growth phase were trypsinized and plated out on 96-well plates at a density of $5 \cdot 10^{4}$ cells/well in $100 \mu \mathrm{L}$ of the culture medium. After overnight growth, the medium was replaced with the fresh one containing a different volume ratio of fruit wine (1-20\%). Following $72 \mathrm{~h}$ of exposure, $10 \mu \mathrm{L}$ of WST-1 were added to each well and cells were incubated for further $3 \mathrm{~h}$. The absorbance was measured at $450 \mathrm{~nm}$ on the microplate reader (Tecan, Männedorf, Switzerland). The experiments were performed in triplicate with three repetitions for each volume ratio of fruit wine. The cell viability was expressed as a percentage of unexposed control cells.

\section{Morphological assessment by fluorescent microscopy}

MCF-7 cells were seeded in chambers of culture slides (BD Biosciences, Erembodegem, Belgium) at the initial concentration of $10^{5}$ cells $/ \mathrm{mL}$, allowed to attach for 24 $\mathrm{h}$ and then exposed to $10 \%$ (by volume) of fruit wines for $72 \mathrm{~h}$. Following exposure, the cells were washed with sterile PBS and stained with a mixture of Acridine Orange $(100 \mu \mathrm{g} / \mathrm{mL}$ in PBS) and ethidium bromide $(100 \mu \mathrm{g} / \mathrm{mL}$ in PBS) for $10 \mathrm{~min}$. The cells were examined using the fluorescent microscope Olympus BX51 (Olympus, Tokyo, Japan) with an integrated camera.

\section{Statistical analysis}

Statistical data analysis was carried out by means of the analysis of variance (ANOVA) using the STATISTICA v. 7 software (StatSoft Inc., Tulsa, OK, USA). Tukey's honestly significant difference (HSD) test $(\mathrm{p}<0.05)$ was used for comparison when samples differed significantly after ANOVA was performed. Pearson's correlation coefficients were used to establish the relationship between the phenolic content and the antioxidant capacity as well as cytotoxicity.

\section{Results and Discussion}

\section{Total phenolics and total anthocyanins in fruit wines}

Wines produced from different fruit sources showed large variations in concentrations of total phenolics and total anthocyanins determined by spectrophotometry (Ta- ble 1). The average content of total phenolics was the highest in cherry, blackcurrant and blackberry wines, moderate in raspberry and strawberry wines, and the lowest in apple wines. Similar ranking trends among fruit wines in the content of total phenolics have been observed earlier by various authors $(23,24,33)$, particularly the apple wines with the lowest values among aforementioned wines. Although the highest average value was determined in cherry wines, the sample of blackcurrant wine, among all thirty-two wine samples, exhibited the maximal value of total phenolics determined as GAE of 3086 $\mathrm{mg} / \mathrm{L}$. On the contrary, the minimal value of approx. 225 $\mathrm{mg} / \mathrm{L}$ was found in the sample of apple wine, as indicated earlier. Concentrations of total phenolics obtained in this research were in line with the literature data, although some small variations regarding the fruit type were noticed. For instance, similar or even higher concentrations of total phenolics were found in cherry and blackcurrant wines, compared to previously reported $850-1940 \mathrm{mg} / \mathrm{L}$ in the former and $520-2380 \mathrm{mg} / \mathrm{L}$ in the latter $(16,23,24,34)$. Furthermore, blackberry wines have been more extensively studied than other fruit wines, especially in Croatia. Our results were slightly higher than $601-1400 \mathrm{mg} / \mathrm{L}$ reported by Arozarena et al. (10) and Ortiz et al. (12), as well as slightly lower than $2212(1052-3621) \mathrm{mg} / \mathrm{L}$ as reported by Johnson and Gonzalez de Mejia (22). On the other hand, results were consistent with the average concentration and/or ranges obtained in 17 and 4 samples of commercial blackberry wines from Croatia, equal to 1548 (733-2698) mg/L (13) and 1697-2628 mg/L (14), respectively. Moreover, concentrations of total phenolics found in raspberry wines were more than $60 \%$ higher compared to earlier indicated $977 \mathrm{mg} / \mathrm{L} \mathrm{(23),} \mathrm{and} \mathrm{slightly} \mathrm{lower} \mathrm{than}$ concentrations found in cherry wine. Also, the existing literature data on strawberry wines show a lower content of phenolics, ranging from $117-525 \mathrm{mg} / \mathrm{L} \mathrm{(35),} \mathrm{than} \mathrm{our}$ results. In addition, concentrations of total phenolics determined in apple wines were consistent with those previously studied, reporting 228-801 mg/L (11,12, 23,24). Concentrations of total phenolics found in blackcurrant, cherry and blackberry fruit wines were close to those found in red wine (1018-4059 mg/L) (36-38). On the other

Table 1. Spectrophotometric characterization of total phenolics and anthocyanins in different commercial fruit wines

\begin{tabular}{lcccccc}
\hline \multirow{2}{*}{ Fruit wine } & \multicolumn{2}{c}{$\gamma$ (total phenolics as GAE) } & & \multicolumn{2}{c}{$\gamma$ (total anthocyanins) } \\
\cline { 2 - 3 } \cline { 6 - 7 } & \multicolumn{2}{c}{$\mathrm{mg} / \mathrm{L}$} & & \multicolumn{2}{c}{$\mathrm{mg} / \mathrm{L}$} \\
\hline Blackberry & $1055.0-2704.5$ & $1936.3^{\mathrm{b}}$ & & $23.2-216.6$ & $90.2^{\mathrm{a}}$ \\
Cherry & $1081.4-2711.4$ & $2074.9^{\mathrm{b}}$ & & $55.1-483.0$ & $244.0^{\mathrm{b}}$ \\
Raspberry & $1199.1-1840.0$ & $1599.7^{\mathrm{ab}}$ & & $117.3-160.6$ & $134.8^{\mathrm{ab}}$ \\
Blackcurrant & $940.9-3086.4$ & $2013.6^{\mathrm{b}}$ & & $70.9-430.1$ & $250.5^{\mathrm{b}}$ \\
Strawberry & $670.5-833.6$ & $752.0^{\mathrm{ab}}$ & & tr-8.3 & $4.2^{\mathrm{a}}$ \\
Apple & $224.6-644.6$ & $449.7^{\mathrm{a}}$ & & - & - \\
\hline
\end{tabular}

Data are expressed as the range and average value in number $(N)$ of samples (see Materials and Methods) of each fruit wine. ANOVA was used to compare the data; different letters indicate statistical differences between different fruit wines (Tukey's test, $\mathrm{p}<0.05)$. GAE=gallic acid equivalent, tr=traces 
hand, concentrations of total phenolics in apple wines were similar to those in white wine $(239-657 \mathrm{mg} / \mathrm{L})$ $(36,37,39)$, while in strawberry and raspberry wines were in-between average values previously reported in white and red wines. Similarly, Rupasinghe and Clegg (23) reported that the concentrations of phenolics in elderberry, blueberry and blackcurrant wines were comparable to red, and in apple and peach wines to white wine.

The average concentration of total anthocyanins determined by the bisulfite bleaching method in fruit wines declined in this order: blackcurrant, cherry, raspberry, blackberry and strawberry wine, while in the apple wine, as expected, anthocyanins were not detected (Table 1). Concentration of total anthocyanins among fruit wines followed the identical pattern as that of total phenolics, with the exception of raspberry and blackberry wines. Namely, opposite to total phenolics, the average concentration of total anthocyanins in the raspberry wine was higher than in the blackberry wine. Interestingly, this result indicates a greater contribution of anthocyanins to the overall phenolic content of the raspberry wine. Nevertheless, in quantitative amounts and relative percentages, blackcurrant and cherry wines represented the first group with a significantly higher concentration of anthocyanins than other fruit wines, followed by the raspberry wine in the second and blackberry, strawberry and apple wines in the third group. Unlike the total phenolic content, comparative studies of total anthocyanins, and even the ones conducted on a particular fruit wine are very scarce and more focused on the composition of individual free anthocyanins. Nevertheless, our results on anthocyanin content were generally in accordance with $(13,14,22,34,40)$ or higher than (18) the ones reported by other authors.

\section{Individual phenolic compounds of fruit wines}

The analysis of individual phenolic compounds including phenolic acids, flavan-3-ols, flavonols and free anthocyanins showed a characteristic phenolic composition of each type of fruit wine, especially as regards anthocyanins (Table 2). Wide concentration ranges of individual phenolic compounds that were obtained within a particular fruit wine could be attributed to the effect of variety (11), geographical origin (13), maturity (40), winemaking technology $(16-18,21,35)$ and phenolic changes that occur during ageing $(15,20)$ and, moreover, to the synergistic effect of the mentioned factors. Fruit wines showed qualitative and quantitative differences in the profile of phenolic acids (Table 2). Average values show that the most abundant phenolic acid in the blackberry wine was gallic acid, with concentrations corresponding to those indicated by other authors $(13,14)$. However, the average concentration of this phenolic acid was not excessively superior to other phenolic acids as indicated earlier (13), but it was higher than average concentrations of epicatechin (14). Interestingly, raspberry and blackcurrant wines also had the highest concentration of gallic acid among the analyzed phenolic acids, but it was much lower compared to the blackberry wine. There has been very little research into the content of phenolic acids in raspberry and blackcurrant wines $(16,21)$ and, compared to it, our results showed lower concentrations. On the other hand, the most represented phenolic acid in cherry and apple wines was chlorogenic acid. These findings and the overall composition and concentration of phenolic acids agree with the results of other authors $(11,16,18)$. In addition, study of Pantelić et al. (34) showed previously that the caffeic, chlorogenic, protocatechuic and $p$-coumaric acids are the main phenolic acids in cherry wine, which is consistent with our results. Unlike all other fruit wines, the most represented phenolic acid in strawberry wine was $p$-coumaric acid, followed by gallic acid. The total content of phenolic acids calculated as a sum of individually determined phenolic acids did not indicate significant differences among fruit wines. However, the highest overall concentrations of phenolic acids were detected in cherry and blackberry wines, followed by strawberry and apple wines, while the lowest concentrations were measured in raspberry and blackcurrant wines.

Flavan-3-ols, catechin and epicatechin, were detected in all fruit wine samples except in the samples of blackcurrant wine, as shown in Table 2. Epicatechin was the most abundant flavan-3-ol monomer in raspberry, blackberry, cherry and apple wines, while catechin was predominant in the raspberry wine. The quantitative analysis of flavan-3-ols in Spanish (41) and Dutch (42) food products showed the identical relation between catehin and epicatechin in the raw fruits specified above. The sum of flavan-3-ols determined in this work in fruit wines decreased in the order: raspberry, blackberry, apple, cherry and strawberry. However, the highest total concentration of flavan-3-ols among all wine samples was detected in one sample of blackberry wine. The concentration of flavan-3-ols in samples of fruit wines was in general comparable to that of fruits proposed by Arts et al. (42), where the highest amounts were determined in blackberry, lowest in strawberry and particularly in blackcurrant, while average in raspberry, apple and sweet cherry. Moreover, our results were similar to the values previously reported for wines produced from blackberries (14) and cherries (17), higher than values established earlier in apple wine (11) and lower than those reported for blackcurrant wine (17).

The highest concentration of quercetin (Table 2) was found in the blackberry wine, followed by raspberry, blackcurrant and cherry wines, while the lowest in strawberry and apple wines. Moreover, the highest concentration was found in one sample of blackberry wine, reaching $17.94 \mathrm{mg} / \mathrm{L}$. Vuorinen et al. (43) analysed 16 samples of red berry and grape wines and reported $2.2-24.3 \mathrm{mg} / \mathrm{L}$ of quercetin in berry wines and $<1.2$ to $19.4 \mathrm{mg} / \mathrm{L}$ in grape wines. Also, Frankel et al. (36) found $2.1-17.1 \mathrm{mg} / \mathrm{L}$ in selected Californian wines. From these data it can be concluded that concentrations of quercetin in the series of blackberry, raspberry, blackcurrant and cherry wines were generally comparable to or lower than those reported in red wines, unlike the ones detected in strawberry and apple wines, which were lower.

Cyanidin glycoside derivatives were predominant anthocyanins identified in blackberry, cherry and raspberry wines. More precisely, the main anthocyanins identified in blackberry wine were cyanidin-3-rutinoside followed by cyanidin-3-glucoside, which is consistent with other studies $(10,12,15)$. Furthermore, cyanidin-3-glucosylrutinoside was the most abundant anthocyanin found in the 
Table 2. HPLC analysis of the concentrations of phenolic acids, flavan-3-ols, flavonols and anthocyanins in different commercial fruit wines

\begin{tabular}{|c|c|c|c|c|c|c|}
\hline & \multicolumn{6}{|c|}{ Fruit wine } \\
\hline & Blackberry & Cherry & Raspberry & Blackcurrant & Strawberry & Apple \\
\hline \multicolumn{7}{|l|}{$\gamma($ phenolic acid $) /(\mathrm{mg} / \mathrm{L})$} \\
\hline Gallic acid & $\begin{array}{c}10.82-52.34 \\
27.82^{*}\end{array}$ & $\begin{array}{l}\operatorname{tr}-5.66 \\
1.60^{*}\end{array}$ & $\begin{array}{c}8.24-10.51 \\
9.37^{*}\end{array}$ & $\begin{array}{c}0.66-4.87 \\
2.76^{*}\end{array}$ & $\begin{array}{c}9.16-11.42 \\
10.29^{*}\end{array}$ & $\begin{array}{c}0.13-1.44 \\
0.77^{*}\end{array}$ \\
\hline Protocatechuic acid & $\begin{array}{c}13.83-62.59 \\
26.42^{*}\end{array}$ & $\begin{array}{c}\operatorname{tr}-15.42 \\
6.47^{*}\end{array}$ & - & $\begin{array}{c}\operatorname{tr}-3.24 \\
1.62^{*}\end{array}$ & - & - \\
\hline Syringic acid & - & - & - & - & $\begin{array}{c}4.82-4.96 \\
4.89^{*}\end{array}$ & - \\
\hline Chlorogenic acid & - & $\begin{array}{c}12.17-110.45 \\
43.27^{*}\end{array}$ & $\begin{array}{c}0.16-2.38 \\
1.27^{*}\end{array}$ & $\begin{array}{l}\operatorname{tr}-3.41 \\
1.71^{*}\end{array}$ & - & $\begin{array}{c}6.19-25.68 \\
15.80^{*}\end{array}$ \\
\hline$p$-Coumaric acid & $\begin{array}{c}0.11-79.69 \\
24.56^{*}\end{array}$ & $\begin{array}{c}0.19-22.23 \\
7.16^{*}\end{array}$ & - & $\begin{array}{c}0.03-0.53 \\
0.28^{*}\end{array}$ & $\begin{array}{c}1.76-44.02 \\
22.89^{*}\end{array}$ & $\begin{array}{c}\operatorname{tr}-0.21 \\
0.12^{*}\end{array}$ \\
\hline Ferulic acid & - & $\begin{array}{c}1.85-13.43 \\
4.00^{*}\end{array}$ & $\begin{array}{c}0.40-3.93 \\
2.75^{*}\end{array}$ & - & - & - \\
\hline Caffeic acid & - & $\begin{array}{c}1.70-46.30 \\
15.46^{*} \\
\end{array}$ & - & $\begin{array}{c}\operatorname{tr}-2.98 \\
1.49^{*}\end{array}$ & $\begin{array}{l}\operatorname{tr}-2.08 \\
1.04^{*}\end{array}$ & $\begin{array}{c}1.09-5.44 \\
3.74^{*}\end{array}$ \\
\hline \multicolumn{7}{|l|}{$\gamma($ flavan-3-ol)/(mg/L) } \\
\hline$(+)$-Catechin & $\begin{array}{c}1.66-10.29 \\
5.74^{*}\end{array}$ & $\begin{array}{c}0.36-11.17 \\
4.86^{*}\end{array}$ & $\begin{array}{c}5.44-15.40 \\
11.06^{*}\end{array}$ & - & $\begin{array}{c}7.04-8.13 \\
7.58^{*}\end{array}$ & $\begin{array}{c}1.52-15.23 \\
9.88^{*}\end{array}$ \\
\hline (-)-Epicatechin & $\begin{array}{c}0.12-61.40 \\
20.43^{*}\end{array}$ & $\begin{array}{c}0.51-24.06 \\
10.98^{*}\end{array}$ & $\begin{array}{c}21.65-43.59 \\
32.13^{*}\end{array}$ & - & $\begin{array}{c}1.53-2.01 \\
1.77^{*}\end{array}$ & $\begin{array}{c}4.14-25.91 \\
10.24^{*}\end{array}$ \\
\hline \multicolumn{7}{|l|}{$\gamma($ flavonol $) /(\mathrm{mg} / \mathrm{L})$} \\
\hline Quercetin & $\begin{array}{c}0.39-17.94 \\
4.51^{*}\end{array}$ & $\begin{array}{c}0.26-3.91 \\
1.88^{*}\end{array}$ & $\begin{array}{c}1.96-3.92 \\
3.16^{*}\end{array}$ & $\begin{array}{c}2.00-3.85 \\
2.93^{*}\end{array}$ & $\begin{array}{c}0.31-1.68 \\
0.99^{*}\end{array}$ & $\begin{array}{c}0.40-0.92 \\
0.73^{*}\end{array}$ \\
\hline \multicolumn{7}{|l|}{$\gamma($ anthocyanin $) /(\mathrm{mg} / \mathrm{L})$} \\
\hline Delphinidin-3-rutinoside & - & - & - & $\begin{array}{c}24.04-179.21 \\
101.63^{*}\end{array}$ & - & - \\
\hline Delphinidin-3-glucoside & - & - & - & $\begin{array}{c}2.20-26.74 \\
14.47^{*}\end{array}$ & - & - \\
\hline Cyanidin-3-sophoroside & - & - & $\begin{array}{c}57.83-124.69 \\
80.98^{*}\end{array}$ & - & - & - \\
\hline Cyanidin-3-glucosylrutinoside & - & $\begin{array}{c}7.37-361.28 \\
132.26^{*}\end{array}$ & $\begin{array}{c}4.89-25.29 \\
11.87^{*}\end{array}$ & - & - & - \\
\hline Cyanidin-3-glucoside & $\begin{array}{c}0.39-25.51 \\
2.96^{*}\end{array}$ & $\begin{array}{c}0.78-12.07 \\
4.95^{*}\end{array}$ & - & - & - & - \\
\hline Cyanidin-3-rutinoside & $\begin{array}{c}1.92-119.33 \\
37.35^{*}\end{array}$ & $\begin{array}{c}3.21-91.44 \\
30.68^{*}\end{array}$ & $\begin{array}{c}5.94-10.72 \\
8.96^{*}\end{array}$ & $\begin{array}{c}16.16-88.77 \\
52.46^{*}\end{array}$ & - & - \\
\hline
\end{tabular}

Data are expressed as range and average value $\left(^{*}\right)$ in number $(N)$ of samples (see Materials and Methods) of each fruit wine. tr=traces

cherry wine, followed by cyanidin-3-rutinoside and cyanidin-3-glucoside, as indicated earlier $(16,18,19)$. The raspberry wine had the highest concentration of cyanidin-3-sophoroside, followed by cyanidin-3-glucosylrutinoside and cyanidin-3-rutinoside, as noted previously (20). On the other hand, delphinidin glycoside derivatives including the most abundant delphinidin-3-rutinoside and the least abundant delphinidin-3-glucoside, as well as cyanidin-3-rutinoside were identified in the blackcurrant wine, as proposed earlier (17). Free anthocyanins were not detected in apple and strawberry wines. This was no surprise for the apple wine, since very low concentrations of anthocyanins were found in apples, with cyanidin-3-galactoside as the major pigment mainly located in the skin and traces found in other parts (44). However, due to the content of anthocyanins of $200-800 \mathrm{mg}$ per $\mathrm{kg}$ of fresh mass $(40,45)$ in strawberry, higher concentrations were expected in strawberry wine. Nevertheless, it is important to note that a wine reflects only in part the phenolic composition of the raw fruit material, as determined for anthocyanins in grapes and wine (46). Hence, it has been suggested that anthocyanin fingerprints of the wine relative to grapes might be the consequence of different extraction rates of anthocyanins, or some degradation reactions that occur during winemaking. For example, the instability of cyanidin-3-glucoside during fermentation observed in blackberry (15) and red raspberry wines (20) is considered to be responsible for the lower concentration of this compound in the wines compared to the fruits. In addition, the pigment analysis of the strawberry wine conducted earlier showed a significant decrease of anthocyanin content after fermentation, where only 3-9\% of 
anthocyanins present in fruits were retained, as well as their progressive decrease throughout the storage (40). Specifically, the decrease of free anthocyanins, due to the formation of pyranoanthocyanins, ethyl-bridged compounds and derived pigments, occurs during wine ageing (47). Therefore, the composition and stability of strawberry anthocyanins based on pelargonidin-3-glucoside as the predominant anthocyanin, followed by pelargonidin-3-rutinoside and cyanidin-3-glucoside (45) is probably responsible for these results, as well as their interactions with other phenolic compounds occurring during winemaking and ageing. Trends in concentration range of total anthocyanins among fruit wines were similar to those of total anthocyanins, but with no significant difference in-between wines due to the wide concentration ranges mentioned earlier.

\section{Antioxidant capacity of fruit wines}

Antioxidant capacities of fruit wines determined by two different assays, ABTS (Fig. 1a) and FRAP (Fig. 1b), demonstrated similar global trends, proving that both assays are appropriate for measuring the antioxidant capacity of different samples of fruit wines. Both ABTS and FRAP assays were well correlated $(\mathrm{R}=0.862, \mathrm{p}<0.001)$. Blackberry, cherry, raspberry and blackcurrant wines had a significantly higher antioxidant capacity than strawberry and apple wines. Similarly, Kalkan Yildirim (33) reported decreasing antioxidant activity of fruit wines in this order: bilberry, blackberry, black mulberry, sour cherry, strawberry, raspberry, apricot, quince, apple and mel-
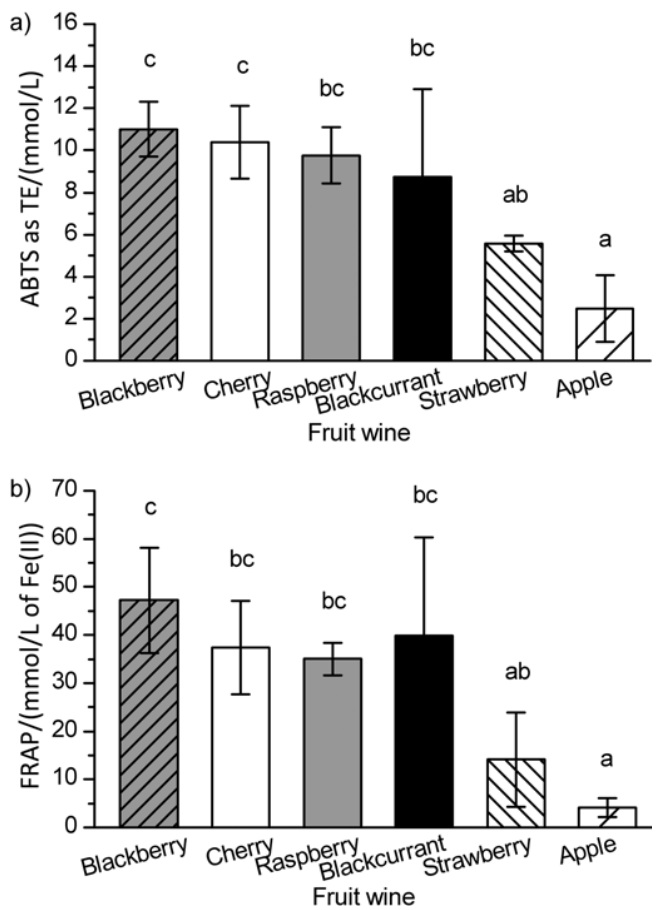

Fig. 1. Antioxidant capacity of different commercial fruit wines determined by: a) ABTS and b) FRAP methods. Data are presented as mean value \pm standard deviation as error bar in number $(N)$ of samples (see Materials and Methods) of each fruit wine. ANOVA was used to compare the data; different letters indicate significant differences between fruit wines (Tukey's test, $\mathrm{p}<0.05$ ) on. A strong positive correlation was confirmed between the phenolic content of fruit wines and their antioxidant capacity measured by ABTS $(\mathrm{R}=0.854, \mathrm{p}<0.001)$ and FRAP $(\mathrm{R}=0.902, \mathrm{p}<0.001)$ assays, as proposed earlier by numerous studies $(10,11,23,36,37)$. Thus, blackberry, cherry and blackcurrant wines with the highest concentrations of total phenolics, as expected, exhibited the highest antioxidant capacity. However, the raspberry wine was a certain surprise. Despite a slightly lower content of total phenolics, the antioxidant capacity of the raspberry wine was in line with the three above-mentioned wines. These findings imply that some individual phenolic compounds or fractions, particularly if present in a higher ratio in the overall phenolic content, could contribute more to the antioxidant properties of the wine than others. For instance, it was shown that a large percentage of antioxidant power (reducing ability) of red wine can be directly correlated with its flavonoid and catechin concentrations (39). Also, the fraction of free anthocyanins was also given a significant importance $(38,48)$. Nevertheless, the antioxidant capacity of fruit wines was not correlated with a particular phenolic fraction (anthocyanins, total phenolic acids, total flavan-3-ols or quercetin). However, the contribution of these fractions in relation to their relative amounts and proposed antioxidant efficiency in literature as indicated above, as well as their synergistic effect in the overall antioxidant capacity of the wine cannot be excluded. Hence, a higher phenolic content as well as higher concentrations of phenolic acids and quercetin found in blackberry, anthocyanins and phenolic acids in cherry, flavan-3-ols in raspberry, and anthocyanins in blackcurrant wine seem to be responsible for the noticeable in vitro antioxidant capacity of the four mentioned wines. The blackberry wine, among all fruit wines, had the highest antioxidant capacity measured by both assays, which was in line or even higher than those reported earlier (13). Interestingly, it can be assumed that the anthocyanin fraction in the blackberry wine, due to lower concentrations, contributed less to the overall antioxidant capacity than in cherry, raspberry and blackcurrant wines. Indeed, Arozarena et al. (10) showed that in the Andean blackberry wine, the antioxidant capacity was strongly correlated with the content of ellagitannins, while no significant correlation was found between the antioxidant capacity and the content of anthocyanins. In addition, the results obtained for the antioxidant capacity of fruit wines were comparable to or lower than those of red wine analyzed earlier by the ABTS assay, which ranged from 9.6-41.0 $\mathrm{mmol} / \mathrm{L}$ of TE $(37,38)$ with average values of 18.9 and 29.3 $\mathrm{mmol} / \mathrm{L}$, or by the FRAP assay, ranging from 20.6-101.5 $\mathrm{mmol} / \mathrm{L}$ of $\mathrm{Fe}(\mathrm{II})$ with average values of 26.1 and 47.2 $\mathrm{mmol} / \mathrm{L}(38,39)$. On the other hand, the antioxidant capacity of strawberry and apple wines was similar to those of white wine reported earlier reaching $3.2(1.7-13.8) \mathrm{mmol} / \mathrm{L}$ of TE (37) and 2.2-3.9 mmol/L Fe(II) (39), measured by the ABTS and FRAP methods, respectively.

\section{Cytotoxic effect of selected fruit wines}

The cytotoxicity of six selected fruit wines comprising blackberry, cherry, raspberry, blackcurrant, strawberry and apple, in the volume ratio ranging from 1 to $20 \%$ in MCF-7, CaCo-2 and HeLa cells was evaluated by the WST-1 cell proliferation assay (Fig. 2). Individual phenol- 

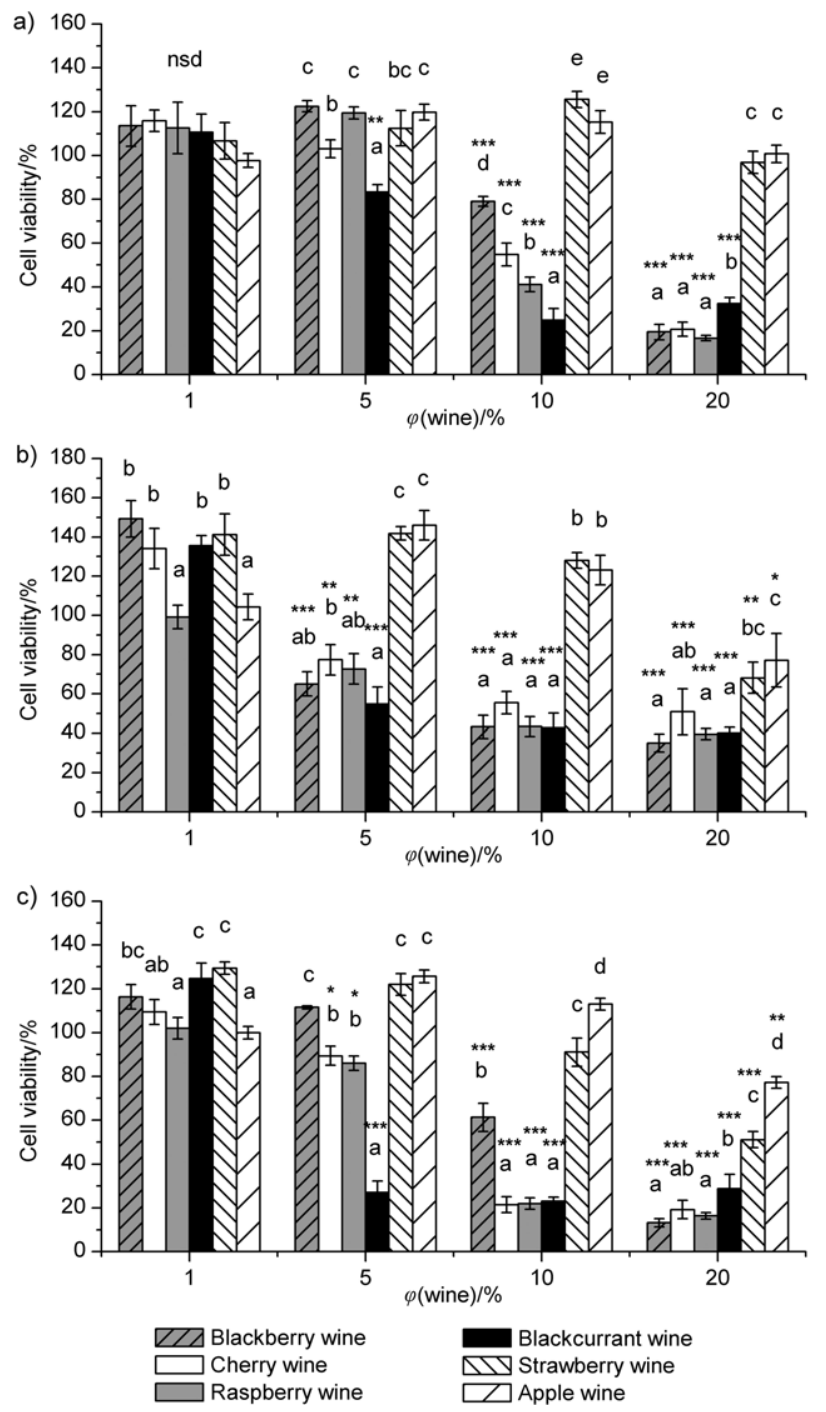

Fig. 2. Effects of six selected fruit wines on the viability of: a) MCF-7, b) CaCo-2 and c) HeLa cells. Data are presented as mean value \pm standard deviation as error bar of three repetitions with three replications for each volume ratio. ANOVA was used to compare the data; different letters indicate significant differences between fruit wines (Tukey's test, $\mathrm{p}<0.05$ ); nsd=no significant differences; asterisk indicates significant cytotoxicity when compared to untreated control cells (Tukey's test, ${ }^{*} \mathrm{p}<0.05,{ }^{* *} \mathrm{p}<$ $\left.0.01{ }^{* * *} \mathrm{p}<0.001\right)$ ic compounds and phenolic extracts of fruit and wine have proven to be very active antiproliferative agents $(25,49,50)$. Hence, the six samples were selected on the basis of given phenolic abundance and diversity among wines (Table 3) in order to study their cytotoxicity effects. Antiproliferative effects of some fruit wines were first noticed at $5 \%$, while $1 \%$ of the tested fruit wines had no inhibitory effect on cell viability in all tested cell lines or even stimulated cell proliferation (Fig. 2). In general, the volume ratio of wine of $5 \%$ and above induced cytotoxic effects in all tested cancer cells. However, the blackcurrant wine was the exception, showing a higher cytotoxic effect on MCF-7 and HeLa cells at 10 than at $20 \%$. Similar to the present results, previous studies have also demonstrated the decrease of cell proliferation in a dose-dependent manner $(25,51)$. However, at high concentrations some polyphenols could act as growth stimulators rather than inhibitors, as reported earlier $(50,52)$ and noticed for the blackcurrant wine.

Different susceptibility among cell lines was also observed, depending on the volume ratio and type of the fruit wine. CaCo- 2 cells demonstrated higher sensitivity at lower volume ratio to a wider spectrum of fruit wines compared to HeLa or MCF-7 cells, while at volume ratios of 10 and $20 \%$, the susceptibility of HeLa cells was higher than that of $\mathrm{CaCo}-2$ and MCF-7 cells. In accordance with this finding, CaCo-2 cells were reported earlier to be generally more sensitive to low concentrations of polyphenol-rich berry extracts, but conversely less sensitive to higher concentrations (53). For instance, $5 \%$ of blackberry, raspberry, cherry and blackcurrant wines induced a significant viability reduction of CaCo-2 cells (Fig. 2b), while raspberry, cherry and blackcurrant wines significantly decreased the viability of HeLa cells (Fig. 2c) and only the blackcurrant wine showed an inhibitory effect on MCF-7 cells (Fig. 2a). Interestingly, at this volume ratio the blackcurrant wine, which was characterized by the highest concentrations of phenolics and anthocyanins, as well as the highest antioxidant capacity, had the strongest cytotoxic effect of on all tested cell lines (Table 3). Furthermore, at the volume ratio of $10 \%$, blackberry, raspberry, cherry and blackcurrant wines demonstrated a significantly lower cell viability compared to the control in all tested cell lines. Still, no significant differences were

Table 3. Phenolic characterization and antioxidant capacity of six selected commercial fruit wines

\begin{tabular}{|c|c|c|c|c|}
\hline \multirow{2}{*}{ Fruit wine } & \multirow{2}{*}{$\frac{\gamma(\text { total phenolics as GAE) }}{\mathrm{mg} / \mathrm{L}}$} & \multirow{2}{*}{$\frac{\gamma \text { (total anthocyanins) }}{\mathrm{mg} / \mathrm{L}}$} & \multicolumn{2}{|c|}{ Antioxidant capacity } \\
\hline & & & ABTS as TE/(mmol/L) & $\mathrm{FRAP} /(\mathrm{mmol} / \mathrm{L}$ of $\mathrm{Fe}(\mathrm{II}))$ \\
\hline Blackberry & $(1424.6 \pm 15.0)^{\mathrm{b}}$ & $(23.2 \pm 0.6)^{\mathrm{a}}$ & $(11.48 \pm 0.03)^{\mathrm{d}}$ & $(33.75 \pm 0.08)^{c}$ \\
\hline Cherry & $(2647.7 \pm 3.2)^{\mathrm{d}}$ & $(174.1 \pm 1.2)^{\mathrm{c}}$ & $(12.04 \pm 0.10)^{\mathrm{d}}$ & $(37.34 \pm 0.25)^{d}$ \\
\hline Raspberry & $(1840.0 \pm 10.3)^{\mathrm{c}}$ & $(160.6 \pm 0.6)^{b}$ & $(9.94 \pm 0.19)^{\mathrm{c}}$ & $(36.61 \pm 0.21)^{d}$ \\
\hline Blackcurrant & $(3086.4 \pm 19.3)^{\mathrm{e}}$ & $(430.1 \pm 5.6)^{\mathrm{d}}$ & $(11.69 \pm 0.04)^{\mathrm{d}}$ & $(60.63 \pm 0.08)^{\mathrm{e}}$ \\
\hline Strawberry & $(670.5 \pm 0.6)^{a}$ & - & $(5.31 \pm 0.24)^{\mathrm{b}}$ & $(7.21 \pm 0.40)^{\mathrm{b}}$ \\
\hline Apple & $(644.6 \pm 2.6)^{a}$ & - & $(4.04 \pm 0.53)^{\mathrm{a}}$ & $(5.59 \pm 0.05)^{\mathrm{a}}$ \\
\hline
\end{tabular}

Data are expressed as mean value of two repetitions \pm standard deviation for each selected sample of fruit wine. ANOVA was used to compare the data; different letters indicate significant differences between six selected fruit wines (Tukey's test, $p<0.05$ ). GAE=gallic acid equivalent, TE=Trolox equivalent, $\mathrm{ABTS}=2,2$ '-azinobis-(3-ethylbenzothiazoline-6-sulfonic acid) radical cation assay, FRAP=ferric reducing antioxidant power 
found in cytotoxicity among these four wines on CaCo-2 cells; blackcurrant, raspberry and cherry wines had significantly higher cytotoxic effects than the blackberry wine on HeLa cells; while cytotoxicity determined in MCF-7 cells decreased in this order: blackcurrant, raspberry, cherry and blackberry wine. On the other hand, at the volume ratio of $20 \%$, all tested fruit wines significantly inhibited the growth of $\mathrm{CaCo}-2$ and HeLa cells compared to the control, while only four of them: blackcurrant, blackberry, raspberry and cherry wines inhibited the growth of MCF-7 cells. It is interesting to note that strawberry and apple wines, with the lowest concentrations of total phenolics and anthocyanins and the lowest antioxidant capacity (Table 3), first demonstrated their cytotoxicity at $20 \%$, while all other tested volume ratios even stimulated the cancer cell proliferation. However, the cytotoxic effects of strawberry and apple wines on $\mathrm{CaCo}-2$ and HeLa cells were significantly lower than those of blackberry, raspberry, cherry and blackcurrant wines. In addition, the antiproliferative properties of these four fruit wines (blackberry, raspberry, cherry and blackcurrant) were more pronounced in HeLa and MCF-7 cells than in CaCo-2 cells, and of similar effectiveness except for the blackcurrant wine, which was less effective at higher volume ratios, as indicated earlier. These results match those observed in earlier in vitro studies $(25,49,51)$, where cell lines of different origins have been shown to respond with varying degrees of sensitivity in growth to different phenolic extracts. However, no consistency was observed in the correlation between the phenolic content and the inhibition of cell proliferation. Nevertheless, the antioxidant activity generally showed a high negative correlation with the viable cell number at volume ratios of 10 and $20 \%$.

In order to discriminate cellular changes induced by fruit wines, morphological analysis was performed on Acridine Orange/ethidium bromide-stained MCF-7 cells, after treatment with $10 \%$ of fruit wines (Fig. 3), selected due to the high negative correlation between the viable cell number and the content of total phenolics $(R=-0.923$, $\mathrm{p}<0.01)$, total anthocyanins $(\mathrm{R}=-0.867, \mathrm{p}<0.01)$, as well as the antioxidant capacity measured by ABTS $(R=-0.848$, $\mathrm{p}<0.05)$ and FRAP $(\mathrm{R}=-0.947, \mathrm{p}<0.01)$ assays. Viable control cells are shown in green (Fig. 3a), while after the treatment with blackberry, cherry, raspberry and blackcurrant wines, cells in the late stages of apoptosis or secondary necrosis with reddish and intense orange fluorescence (Figs. 3b-e) can be observed (colour version available at www.ftb.com.hr). Moreover, among these four wines, the raspberry wine and particularly the blackcurrant wine with the highest phenolic content (Table 3) showed intensive disruption of the cell monolayer and clearly reduced the cell density. On the contrary, in cells treated with wines of lower phenolic contents, i.e. strawberry and apple wines (Figs. $3 \mathrm{f}$ and g), the most represented were green, viable cells (colour version available at www.ftb.com.hr) with early apoptotic cells rarely present and shown in yellow. Overall, the obtained results indicate that the cytotoxicity of fruit wines in the tested cancer cells was due to the antiproliferative and apoptotic effects.
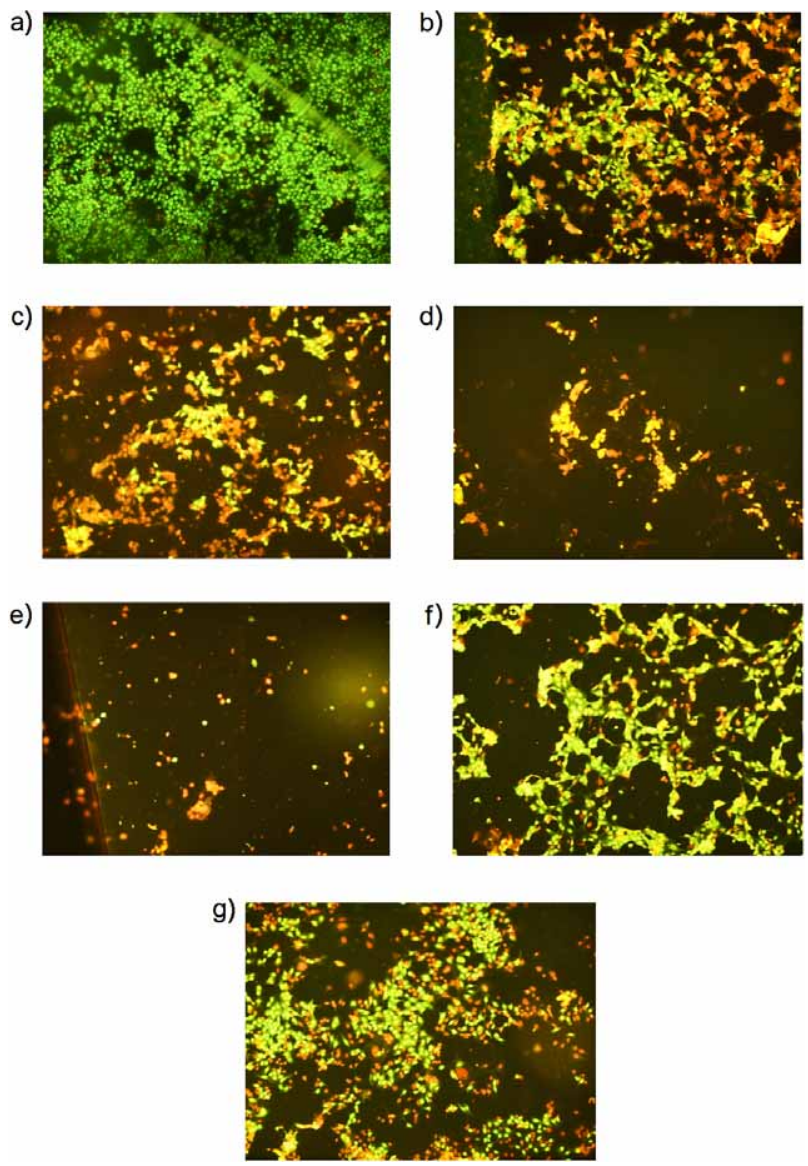

Fig. 3. Photomicrographs of MCF-7 cells after $72 \mathrm{~h}$ of treatment with $10 \%$ (by volume) of selected fruit wines: a) untreated control, b) blackberry wine, c) cherry wine, d) raspberry wine, e) blackcurrant wine, f) strawberry wine and g) apple wine stained with Acridine Orange and ethidium bromide (magnification 100×). Colour figures available at www.ftb.com.hr

\section{Conclusion}

Comprehensive insight into the phenolic content and biological properties of fruit wines produced in Croatia has been shown for the first time. Blackberry, cherry, raspberry and blackcurrant wines compared to strawberry and particularly apple wines had higher concentrations of total phenolics and total anthocyanins determined by spectrophotometry, as well as flavonoids determined by the HPLC analysis (free anthocyanins, flavan-3-ols and quercetin). These wines also showed a higher antioxidant capacity. A strong positive correlation was confirmed between the total phenolic content and antioxidant properties measured by the ABTS $(\mathrm{R}=0.854, \mathrm{p}<0.001)$ and FRAP $(\mathrm{R}=0.902, \mathrm{p}<0.001)$ assays. The cytotoxicity of fruit wines showed to be dependent on their volume ratio, with different susceptibility among the tested cancer cells. Fruit wines with a higher concentration of total phenolics and anthocyanins and with a higher antioxidant capacity exhibited the strongest cytotoxicity towards cancer cells. At lower volume ratios, the blackcurrant wine showed the strongest cytotoxicity among all fruit wines, and the susceptibility of $\mathrm{CaCo}-2$ cells to fruit wines was generally higher than that of HeLa and MCF-7 cells. At higher volume ratios, blackberry, cherry, raspberry and blackcur- 
rant wines significantly inhibited cell proliferation in all tested cell lines compared to strawberry and apple wines, with a higher susceptibility of HeLa and MCF-7 cells to the former group, and HeLa and CaCo-2 cells to the latter.

\section{References}

1. Beckman $\mathrm{CH}$. Phenolic-storing cells: keys to programmed cell death and periderm formation in wilt disease resistance and in general defence responses in plants? Physiol Mol Plant P. 2000;57:101-10. http://dx.doi.org/10.10006/pmpp.2000.0287

2. Luqman S, Rizvi SI. Protection of lipid peroxidation and carbonyl formation in proteins by capsaicin in human erythrocytes subjected to oxidative stress. Phytother Res. 2006;20: 303-6. http://dx.doi.org/10.1002/ptr.1861

3. Pandey KB, Mishra N, Rizvi SI. Protective role of myricetin on markers of oxidative stress in human erythrocytes subjected to oxidative stress. Nat Prod Commun. 2009;4:221-6.

4. Pandey KB, Rizvi SI. Protective effect of resveratrol on markers of oxidative stress in human erythrocytes subjected to in vitro oxidative insult. Phytother Res. 2010;24:S11-4. http://dx.doi.org/10.1002/ptr.2853

5. Graf BA, Milbury PE, Blumberg JB. Flavonols, flavones, flavanones, and human health: epidemiological evidence. J Med Food. 2005;8:281-90. http://dx.doi.org/10.1089/jmf.2005.8.281

6. Arts ICW, Hollman PCH. Polyphenols and disease risk in epidemiologic studies. Am J Clin Nutr. 2005;81:317S-25S.

7. García-Lafuente A, Guillamón E, Villares A, Rostagno MA, Martínez JA. Flavonoids as anti-inflammatory agents: implications in cancer and cardiovascular disease. Inflamm Res. 2009;58:537-52.

http://dx.doi.org/10.1007/s00011-009-0037-3

8. Rodríguez-Delgado MÁ, González-Hernández G, CondeGonzález JE, Pérez-Trujillo JP. Principal component analysis of the polyphenol content in young red wines. Food Chem. 2002;78:523-32.

http://dx.doi.org/10.1016/S0308-8146(02)00206-6

9. Vidal S, Francis L, Guyot S, Marnet N, Kwiatkowski M, Gawel R, et al. The mouth-feel properties of grape and apple proanthocyanidins in a wine-like medium. J Sci Food Agr. 2003;83:564-73. http://dx.doi.org/10.1002/jsfa.1394

10. Arozarena I, Ortiz J, Hermosín-Gutiérrez I, Urretavizcaya I, Salvatierra S, Córdova I, et al. Color, ellagitannins, anthocyanins, and antioxidant activity of andean blackberry (Rubus glaucus Benth.) wines. J Agric Food Chem. 2012;60:7463-73. http://dx.doi.org/10.1021/jf300924z

11. Satora P, Sroka P, Duda-Chodak A, Tarko T, Tuszyński T. The profile of volatile compounds and polyphenols in wines produced from dessert varieties of apples. Food Chem. 2008; 111:513-9. http://dx.doi.org/10.1016/j.foodchem.2008.04.007

12. Ortiz J, Marín-Arroyo MR, Noriega-Domínguez MJ, Navarro $\mathrm{M}$, Arozarena I. Color, phenolics, and antioxidant activity of blackberry (Rubus glaucus Benth.), blueberry (Vaccinium floribundum Kunth.), and apple wines from Ecuador. J Food Sci. 2013;78:C985-93.

http://dx.doi.org/10.1111/1750-3841.12148

13. Amidžić Klarić D, Klarić I, Mornar A. Polyphenol content and antioxidant activity of commercial blackberry wines from Croatia: application of multivariate analysis for geographic origin differentiation. J Food Nutr Res. 2011;50:199209.
14. Mudnic I, Budimir D, Modun D, Gunjaca G, Generalic I, Skroza D, et al. Antioxidant and vasodilatory effects of blackberry and grape wines. J Med Food. 2012;15:315-21. http://dx.doi.org/10.1089/jmf.2011.0129

15. Rommel A, Wrolstad RE, Heatherbell DA. Blackberry juice and wine: processing and storage effects on anthocyanin composition, color and appearance. J Food Sci. 1992;57:38591.

http://dx.doi.org/10.1111/j.1365-2621.1992.tb05500.x

16. Czyzowska A, Pogorzelski E. Changes to polyphenols in the process of production of must and wines from blackcurrants and cherries. Part I. Total polyphenols and phenolic acids. Eur Food Res. Technol. 2002;214:148-54.

http://dx.doi.org/10.1007/s00217-001-0422-9

17. Czyżowska A, Pogorzelski E. Changes to polyphenols in the process of production of must and wines from blackcurrants and cherries. Part II. Anthocyanins and flavanols. Eur Food Res. Technol. 2004;218:355-9. http://dx.doi.org/10.1007/s00217-003-0857-2

18. Sun SY, Jiang WG, Zhao YP. Evaluation of different Saccharomyces cerevisiae strains on the profile of volatile compounds and polyphenols in cherry wines. Food Chem. 2011;127:547-55. http://dx.doi.org/10.1016/j.foodchem.2011.01.039

19. Rentzsch M, Quast P, Hillebrand S, Mehnert J, Winterhalter P. Isolation and identification of 5-carboxy-pyranoanthocyanins in beverages from cherry (Prunus cerasus L.). Innov Food Sci Emerg Tehnol. 2007;8:333-8. http://dx.doi.org/10.1016/j.ifset.2007.03.006

20. Rommel A, Heatherbell DA, Wrolstad RE. Red raspberry juice and wine: effect of processing and storage on anthocyanin pigment composition, color and appearance. J Food Sci. 1990;55:1011-7. http://dx.doi.org/10.1111/j.1365-2621.1990.tb01586.x

21. Duarte WF, Dias DR, Oliveira JM, Vilanova M, Teixeira JA, Almeida e Silva JB, Schwan RF. Raspberry (Rubus idaeus L.) wine: yeast selection, sensory evaluation and instrumental analysis of volatile and other compounds. Food Res Int. 2010;43:2303-14. http://dx.doi.org/10.1016/j.foodres.2010.08.003

22. Johnson MH, Gonzalez de Mejia E. Comparison of chemical composition and antioxidant capacity of commercially available blueberry and blackberry wines in Illinois. J Food Sci. 2012;77:C141-8. http://dx.doi.org/10.1111/j.1750-3841.2011.02505.x

23. Rupasinghe HPV, Clegg S. Total antioxidant capacity, total phenolic content, mineral elements, and histamine concentrations in wines of different fruit sources. J Food Compos Anal. 2007;20:133-7. http://dx.doi.org/10.1016/j.jfca.2006.06.008

24. Heinonen IM, Lehtonen PJ, Hopia AI. Antioxidant activity of berry and fruit wines and liquors. J Agric Food Chem. 1998; 46:25-31. http://dx.doi.org/10.1021/jf970489o

25. Seeram NP, Adams LS, Zhang Y, Lee R, Sand D, Scheuller HS, Heber D. Blackberry, black raspberry, blueberry, cranberry, red raspberry, and strawberry extracts inhibit growth and stimulate apoptosis of human cancer cells in vitro. J Agric Food Chem. 2006;54:9329-39. http://dx.doi.org/10.1021/jf061750g

26. Singleton VL, Rossi Jr JA. Colorimetry of total phenolics with phosphomolybdic-phosphotungstic acid reagents. Am J Enol Vitic. 1965;16:144-58.

27. Ribéreau-Gayon P, Stonestreet E. Determination of anthocyanins in red wine. Bull Soc Chim. 1965;9:2649-52 (in French).

28. Ribéreau-Gayon P. Research of plant anthocyanins: application in Vitis sp. [PhD Thesis]. Paris, France: Lib Gen Enseignement; 1959 (in French). 
29. Wu X, Gu L, Prior RL, McKay S. Characterization of anthocyanins and proanthocyanidins in some cultivars of Ribes, Aronia, and Sambucus and their antioxidant capacity. J Agric Food Chem. 2004;52:7846-56. http://dx.doi.org/10.1021/jf0486850

30. Wu X, Prior RL. Systematic identification and characterization of anthocyanins by HPLC-ESI-MS/MS in common foods in the United States: fruits and berries. J Agric Food Chem. 2005;53:2589-99. http://dx.doi.org/10.1021/jf048068b

31. Re R, Pellegrini N, Proteggente A, Pannala A, Yang M, RiceEvans C. Antioxidant activity applying an improved ABTS radical cation decolorization assay. Free Radic Biol Med. 1999;26:1231-7. http://dx.doi.org/10.1016/S0891-5849(98)00315-3

32. Benzie IFF, Strain JJ. The ferric reducing ability of plasma (FRAP) as a measure of 'antioxidant power' : the FRAP assay. Anal Biochem. 1996;239:70-6. http://dx.doi.org/10.1006/abio.1996.0292

33. Kalkan Yildirim H. Evaluation of colour parameters and antioxidant activities of fruit wines. Int J Food Sci Nutr. 2006; 57:47-63. http://dx.doi.org/10.1080/09637480600655993

34. Pantelić M, Dabić $\mathrm{D}$, Matijašević $\mathrm{S}$, Davidović $\mathrm{S}$, Dojčinović B, Milojković-Opsenica D, et al. Chemical characterization of fruit wine made from oblačinska sour cherry. Sci World J. 2014;Article ID:454797. http://dx.doi.org/10.1155/2014/454797

35. Joshi VK, Sharma S, Bhushan S. Effect of method of preparation and cultivar on the quality of strawberry wine. Acta Aliment. 2005;34:339-53. http://dx.doi.org/10.1556/AAlim.34.2005.4.2

36. Frankel EN, Waterhouse AL, Teissedre PL. Principal phenolic phytochemicals in selected California wines and their antioxidant activity in inhibiting oxidation of human low-density lipoproteins. J Agric Food Chem. 1995;43:890-4. http://dx.doi.org/10.1021/jf00052a008

37. Landrault N, Poucheret P, Ravel P, Gasc F, Cros G, Teissedre PL. Antioxidant capacities and phenolics levels of French wines from different varieties and vintages. J Agric Food Chem. 2001;49:3341-8. http://dx.doi.org/10.1021/jf010128f

38. Rivero-Pérez MD, Muñiz P, González-Sanjosé ML. Contribution of anthocyanin fraction to the antioxidant properties of wine. Food Chem Toxicol. 2008;46:2815-22. http://dx.doi.org/10.1016/j.ftc.2008.05.014

39. Katalinić V, Milos M, Modun D, Musić I, Boban M. Antioxidant effectiveness of selected wines in comparison with (+)-catechin. Food Chem. 2004;86:593-600. http://dx.doi.org/10.1016/j.foodchem.2003.10.007

40. Pilando LS, Wrolstad RE, Heatherbell DA. Influence of fruit composition, maturity and mold contamination on the color and appearance of strawberry wine. J Food Sci. 1985;50: 1121-5.

http://dx.doi.org/10.1111/j.1365-2621.1985.tb13025.x

41. de Pascual-Teresa S, Santos-Buelga C, Rivas-Gonzalo JC. Quantitative analysis of flavan-3-ols in Spanish foodstuffs and beverages. J Agric Food Chem. 2000;48:5331-7. http://dx.doi.org/10.1021/jf000549h
42. Arts ICW, van de Putte B, Hollman PCH. Catechin contents of foods commonly consumed in the Netherlands. 1. Fruits, vegetables, staple foods, and processed foods. J Agric Food Chem. 2000;48:1746-51. http://dx.doi.org/10.1021/jf000025h

43. Vuorinen $H$, Määttä $K$, Törrönen R. Content of the flavonols myricetin, quercetin, and kaempferol in Finnish berry wines. J Agric Food Chem. 2000;48:2675-80. http://dx.doi.org/10.1021/jf991388o

44. Awad MA, de Jager A, van Westing LM. Flavonoid and chlorogenic acid levels in apple fruit: characterisation of variation. Sci Hortic. 2000;83:249-63. http://dx.doi.org/10.1016/S0304-4238(99)00124-7

45. da Silva FL, Escribano-Bailón MT, Pérez Alonso JJ, Rivas-Gonzalo JC, Santos-Buelga C. Anthocyanin pigments in strawberry. LWT - Food Sci Technol. 2007;40:374-82. http://dx.doi.org/10.1016/j.lwt.2005.09.018

46. Revilla E, García-Beneytez E, Cabello F, Martín-Ortega G, Ryan JM. Value of high-performance liquid chromatographic analysis of anthocyanins in the differentiation of red grape cultivars and red wines made from them. J Chromatogr A. 2001;915:53-60. http://dx.doi.org/10.1016/S0021-9673(01)00635-5

47. Atanasova V, Fulcrand H, Cheynier V, Moutounet M. Effect of oxygenation on polyphenol changes occurring in the course of wine-making. Anal Chim Acta. 2002;458:15-27. http://dx.doi.org/10.1016/S0003-2670(01)01617-8

48. Ghiselli A, Nardini M, Baldi A, Scaccini C. Antioxidant activity of different phenolic fractions separated from an Italian red wine. J Agric Food Chem. 1998;46:361-7. http://dx.doi.org/10.1021/jf970486b

49. Matić I, Žižak Ž, Simonović M, Simonović B, Gođevac D, Šavikin K, Juranić Z. Cytotoxic effect of wine polyphenolic extracts and resveratrol against human carcinoma cells and normal peripheral blood mononuclear cells. J Med Food. 2010;13:851-62.

50. Damianaki A, Bakogeorgou E, Kampa M, Notas G, Hatzoglou A, Panagiotou S, et al. Potent inhibitory action of red wine polyphenols on human breast cancer cells. J Cell Biochem. 2000;78:429-41. http://dx.doi.org/10.1002/1097-4644(20000901)78:3<429::AIDJCB8 $>3.0 . C O ; 2-\mathrm{M}$

51. Jeong JH, Jung H, Lee SR, Lee HJ, Hwang KT, Kim TY. Antioxidant, anti-proliferative and anti-inflammatory activities of the extracts from black raspberry fruits and wine. Food Chem. 2010;123:338-44. http://dx.doi.org/10.1016/j.foodchem.2010.04.040

52. Kampa M, Hatzoglou A, Notas G, Damianaki A, Bakogeorgou E, Gemetzi C, et al. Wine antioxidant polyphenols inhibit the proliferation of human prostate cancer cell lines. Nutr Cancer. 2000;37:223-33. http://dx.doi.org/10.1207/S15327914NC372_16

53. McDougall GJ, Ross HA, Ikeji M, Stewart D. Berry extracts exert different antiproliferative effects against cervical and colon cancer cells grown in vitro. J Agric Food Chem. 2008; 56:3016-23. http://dx.doi.org/10.1021/jf073469n 